EESTI NSV TEADUSTE AKADEEMIA TOIMETISED. 28. KOIDE GEOLOOGIA. 1979, NR. 4

ИЗВЕСТИЯ АКАДЕМИИ НАУК ЭСТОНСКОИ ССР. ТОМ 28 ГЕОЛОГИЯ. 1979, № 4

\title{
МОРФОЛОГИЯ И ВОЗРАСТ HALYSITES CATENULARIUS (LINNAEUS)
}

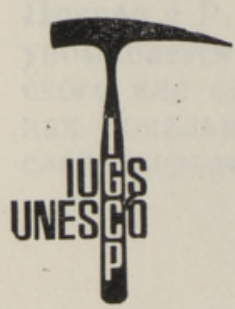

Проект «Экостратиграфия»

Для ревизии рода Halysites, изобилующего синонимичными формами, большое значение имеет изучение его типового рода Halysites catenularius (Linnaeus, 1767), трактуемого в литературе порой совершенно произвольно. Это можно объяснить недостаточным знанием его количественных признаков, полным отсутствием микроскопической характеристики неотипа и тем, что геологический возраст генотипа остался до сих пор неопределенным. Как известно, К. Линней (Linnaeus, 1767) описал рассматриваемый вид по материалу из береговой гальки о. Готланд. В наносных отложениях найден также отобранный Д. Томасом и С. Смитом (Thomas, Smith, 1954) из старой коллекции М. Бромелла (Bromell, 1728) неотип, хранящийся в настоящее время в Палеонтологическом институте Упсальского университета (Швеция).

Нами предпринята попытка внести ясность в проблему об истинных признаках $H$. catenularius путем переизучения неотипа и анализа результатов монографического исследования хализитид о. Готланд в целом. Приведенная синонимика содержит и наши предположения о возможных младших синонимах этого вида.

\section{Halysites catenularius (Linnaeus, 1767)}

Табл. I, фиг. 1; Табл. II, фиг. 1-5

1728. Tubularia fossilis. Bromell (part.), с. 411, № 5, фиг. II в табл., противоположной с. 410.

1767. Tubipora catenularia - Linnaeus, c. 1270.

\section{ТАБЛИЦА I}

Фиг. 1. Неотип Halysites catenularius (Linnaeus). Экз. № G. 681 из коллекции Палеонтологического института, Упсала; $\times 2$.

Хорошо заметны пережимы в местах соединения цепочечно расположенных кораллитов, отмечающие мезокораллиты. В данном полипняке цепочки сильно сближены, между ними находятся длинные узкие лакуны меандрической формы. Возраст - видимо, поздний лландовери.

Фиг. 2. Неотип Catenipora escharoides Lamarck. Экз. № G. 682 из коллекцни Палеонтологического института, Упсала; $\times 2$.

Снимок приведен в качестве сравнения, чтобы доказать необоснованность отнесения escharoides к роду Halysites. Мезокораллиты полностью отсутствуют. Неотип происходит либо из верхнелландоверийских, либо из венлокских отложений о. Готланд. 

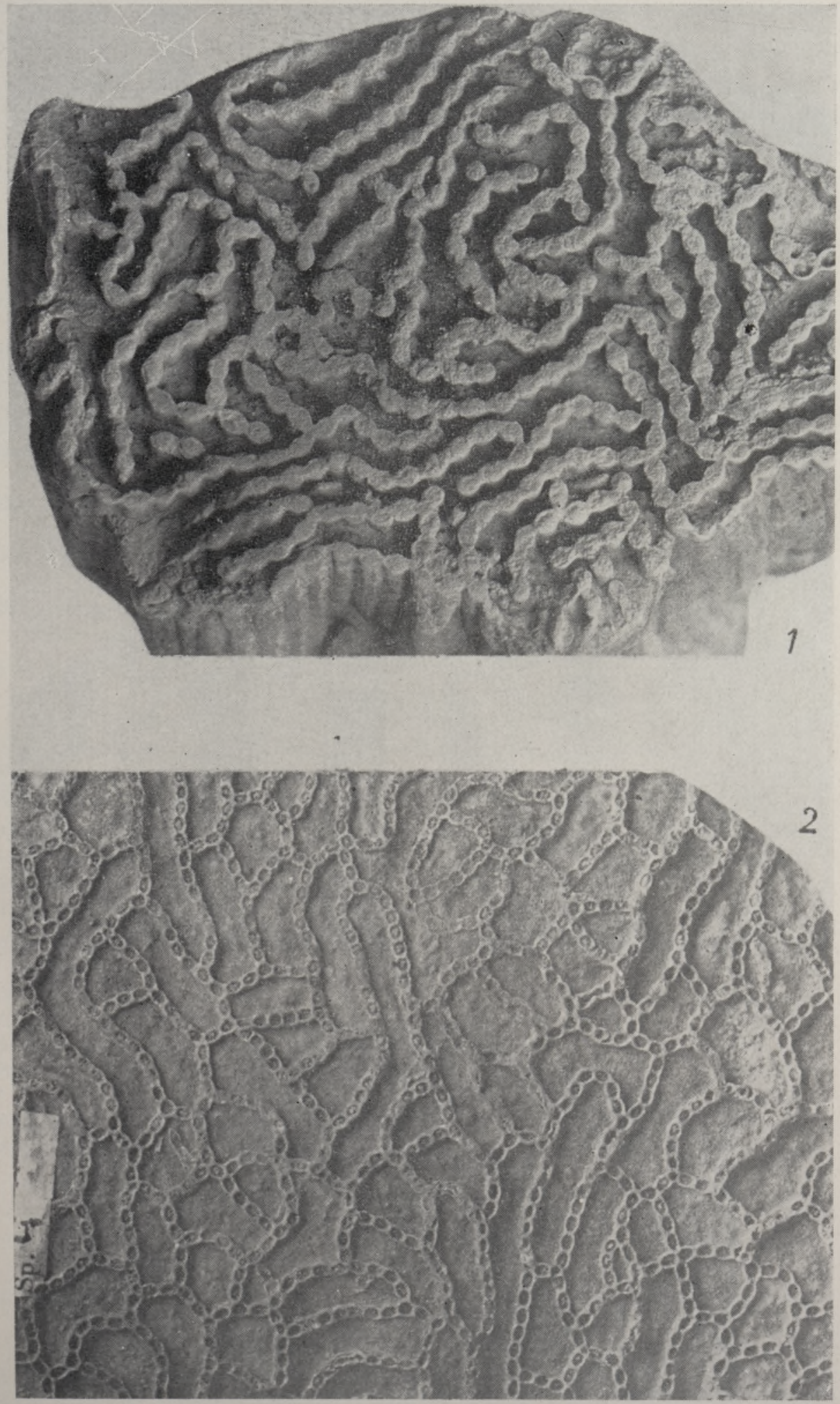

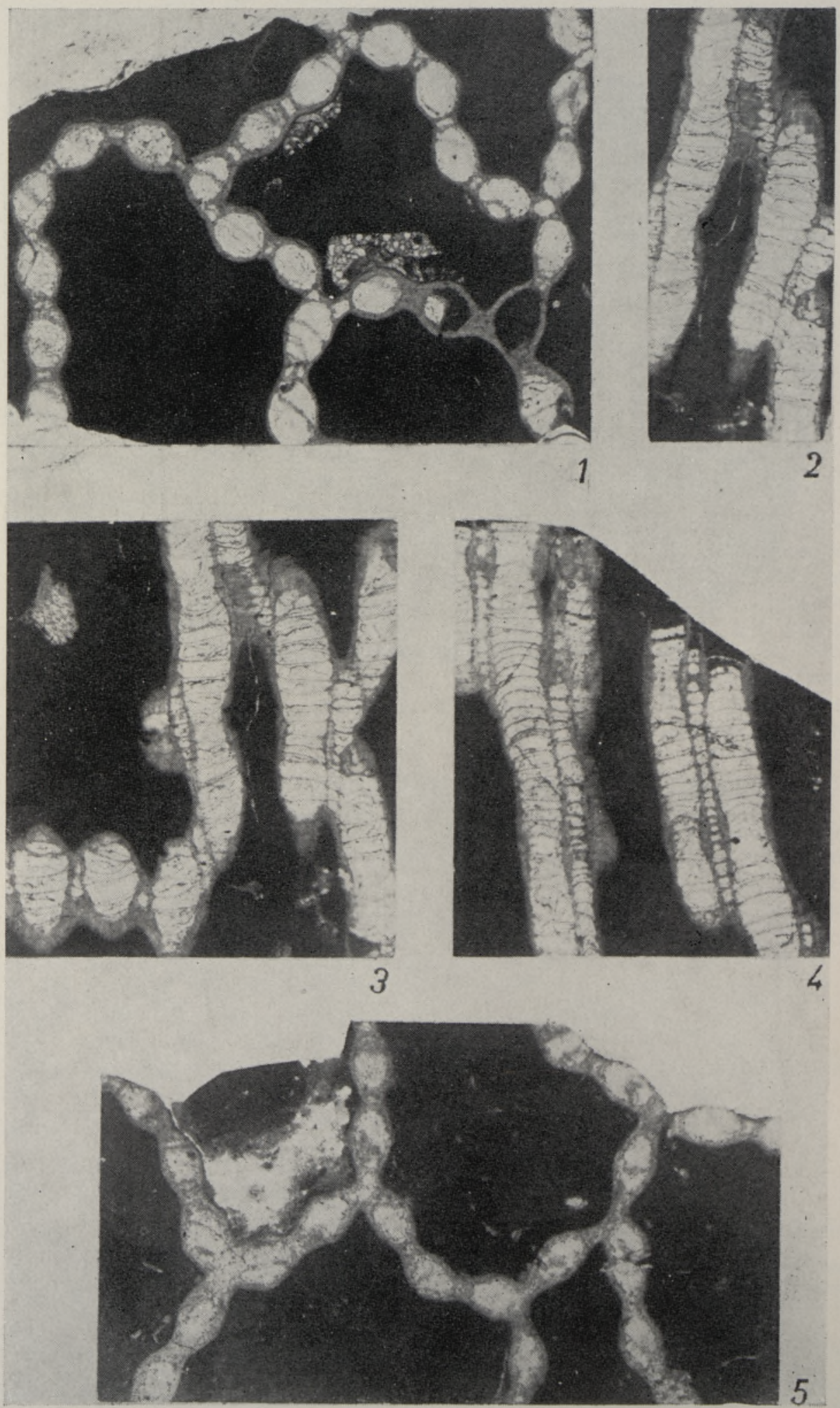
1904. Halysites cratus sp. nov. - Etheridge, с. 27-29, табл. I, фиг. 1; табл. IV, фиг. 3, 4; табл. VI, фиг. 5, 6.

1915. Halysites pycnoblastoides Etheridge - Yabe, c. 36-37, табл. IX (V), фиг. 3, 4.

1915. Halysites pycnoblastoides Etheridge - Yabe and Hayasaka, c. 79.

1920. Halysites pycnoblastoides Etheridge - Yabe and Hayasaka, c. $84-85$, табл. VII, фиг. $3 a, b$.

1925. Halysites cf. cratus Etheridge - Grabau, c. 77.

1937. Halysites catenularius var. borealis n. var. - Чернышев, с. 98-99, табл. XI, фиг. $5 a, b$, рис. 12 в тексте.

1954. Halysites catenularius (Linnaeus) - Thomas and Smith, c. 766, табл. XX, фиг. $1 a-c$.

1955. Halysites catenularius (Linnaeus) - Buehler, c. 24-25.

1955. Halysites cratus Etheridge - Buehler, c. 53-54.

1955. Halysites catenularius var. borealis Tchernychev-Buehler, c. 61 .

1957. Acanthohalysites borealis (Tchernychev) - Hamada, c. 404.

1958. Halysites cratus Etheridge - Hamada, c. 101-102, табл. Х, фиг. $5,6 a-c$.

1958. Acanthohalysites pycnoblastoides yabei subsp. nov. - Hamada, c. $105-106$.

1963. Halysites catenularius (Linnaeus) - Лелешус, с. 181, 184, табл. VI, фиг. 3, 4.

1966. Halysites priscus sp. nov. - Клааманн, с. 60-61, табл. XXII, фиг. 5-7.

Не о ти п. Экз. № 1 из коллекции М. Бромелла (Bromell, 1728, с. 411, № 5, фиг. II в табл., противоположной с. 410). Выбран Д. Томасом и C. Смитом (Thomas, Smith, 1954, с. 766). Происходит из современных береговых отложений Балтийского моря; видимо, вымыт из лландоверийских слоев. Хранится в Палеонтологическом институте в Упсале (Швеция).

Диагно3. Сравнительно тонкостенный Halysites c кораллитами 1,3-1,5×1,6-1,8 мм, собранными в небольшие петли - в поперечнике 10-20 мм. Мезокораллиты четкие. Наблюдаются небольшие септальные шипики.

О пи сание. Полипняк от небольших до средних размеров. Сложен из вытянутых петель различной формы. Чаще всего петли содержат около 20 кораллитов, поперечник оставшихся внутри петель лакун колеблется от 10 до 20 мм, у неотипа - от 1 до 5 мм. Форма и размеры кораллитов хорошо выдержаны: их ширина колеблется от 1,3 до 1,5 мм, длина - от 1,6 до 1,8 мм и лишь в единичных случаях достигает 2,0 мм. Мезокораллиты между ними правильные четырехугольные, размером $0,5-0,6 \times 0,75$ мм (включая и толщину стенок), однако их правильная форма нарушается в местах расхождения цепочек, где

\section{ТАБЛИЦА ІІ}

Halysites catenularius (Linnaeus).

Фиг. 1. Cn 56477; Готланд, Густавсвик I, нижние мергели Висбю. Поперечный разрез; $\times 5$.

В местах слияния цепочек мезокораллиты увеличиваются и приобретают неправильную много- или трехугольную форму.

Фиг. 2-4. Cn 56476; местонахождение и возраст те же. Продольные разрезы; $\times 5$.

Фиг. 5. Сп 57506; Готланд, Иревикен 3, нижние мергели Висбю. Поперечный разрез; $\times 5$.

2 ENSV TA Toimetised. G 41979 
мезокораллиты нередко сильно вытянуты или имеют неправильную трех- или многоугольную форму (табл. II, фиг. 1). Стенки кораллитов и мезокораллитов одинаковой толщины $(0,15-0,2$ мм), и как правило, их вещество представляет собой однородную тонкозернистую массу. В стенках лишь единичных кораллитов заметны короткие темные волокна, ориентированные параллельно поверхности стенок (образуя т. н. псевдоламеллярную вторичную микроструктуру sensu; Oekentorp, 1972). Септальные шипики (12) умеренно развиты; в основном они разрушены в ходе постмортальных преобразований скелета коралла, и от них сохранились только основания в виде коротких зубцов. Днища горизонтальные или слегка вогнутые, с интервалом 0,4-0,7 мм; мезокораллиты диафрагмированы в среднем в два раза гуще.

Из менчи вость. Материал с о. Готланд, как и неотип, обнаруживает большіое постоянство признаков. Например, ширина кораллитов очень редко превышает 1,5 мм и может достигать максимально 1,7 мм. Наибольший диаметр кораллитов находится чаще всего в пределах 1,6-1,9 мм, но почти в каждой колонии возможны небольшие отклонения в меньшую или в бо́льшую сторону. Толщина стенки обычно не выходит за рамки отмеченного в описании интервала и, если это происходит, то только в сторону небольшого увеличения (до 0,25 мм). Наиболее изменчив септальный аппарат, но это скорее результат неудовлетворительной сохранности, чем истинной изменчивости. Можно утверждать, что Halysites catenularius, вопреки многим высказываниям, имел септальные шипики и поэтому к самостоятельности ряда сходных видов хализитов, установленных только по небольшим различиям септального аппарата, следует относиться весьма критично.

3 а меч ания. На основе изложенного можно заключить, что из известных по литературе видов хализитов с Halysites catenularius идентичны $H$. cratus Etheridge и $H$. pycnoblastoides Etheridge - последний только в трактовке японских палеонтологов. Как показало изучение синтипов $H$. pycnoblastoides, хранящихся в Токийском университете (Hamada, 1958, с. 106), кораллиты этого вида австралийского происхождения из коллекции Р. Этериджа значительно меньше $(1,0 \times 1,5 \mathrm{Mм})$, чем кораллиты китайского происхождения, обозначенные тем же видовым названием в работах X. Ябе, Х. Ябе и И. Хайасака и Т. Хамада (см. синонимику). Из видов, описанных советскими авторами, младшими синонимами являются Halysites catenularius var. borealis Б. Б. Чернынева и $H$. priscus Э. Клааманна. Об этом свидетельствует сравнение размеров отдельных элементов скелета названных видов с таковыми готландских Halysites catenularius (таблица). Объединению этих видов не противоречит и их геологический возраст (у всех лландовери).

Ревизия хализитид о. Готланд показывает, что формы, во всем идентичные с неотипом Halysites catenularius, встречаются только в нижних мергелях Висбю, т. е. не выходят за границы лландовери. Предположения, высказанные некоторыми коллегами в частных беседах, о том, что к этому виду относятся хализиты и из слоев Клинтеберг (их лакуны заполнены таким же зеленовато-желтым матриксом, как у неотипа) или Мульде, детальными морфологическими исследованиями не подтвердились. Клинтебергские и мульдеские хализиты о. Готланд имеют совершенно иную (более толстую и многослойную) стенку кораллитов, у них лучше развит септальный аппарат и кораллиты более крупные - их наибольший диаметр редко бывает менее 2,0 M.M.

В силурийском бассейне Балтоскандии $H$. catenularius был редким 
видом. Имеющиеся находки все без исключения происходят из отложений, накопившихся в более глубоководной части открытого шельфа.

С р а внение. По величине кораллитов Halysites catenularius весьма близок к H. amplitubata Buehler из силура о. Антикости (Buehler, 1955 , с. 48 , табл. 8 , фиг. 2,3$)$, но отличается от него наличием длинных вытянутых мезокораллитов. Более крупны кораллиты у $H$. densus Mironova из лудлова Салаира (Миронова, 1965, с. 136, табл. XXXIII, фиг. $1 a$, б) $-1,5-1,8 \times 1,8-2,2$ мм.

Р асп постранени е. О. Готланд, нижние мергели Висбю; Эстония, юуруский горизонт; Северная Земля, о. Голомянный, лландовери; Центральный Китай, «средний готландий»; Япония, известняки у Фуками, силур, слои $\mathrm{G}_{3}$; Австралия, Новый Южный Уэльс, нижний силур.

Местон ахождени е. О. Готланд, Стенчюрка, Иревикен 3, (Stenkyrka, Ireviken 3), коллекция А. Мартинссона, Cn 57506; Висбю, Густавсвик I (Visby, Gustavsvik I), коллекция Э. Ярвика, Cn 56476 и Cn 56477.

\section{Сравнение Halysites catenularius с синонимичными видами}

\begin{tabular}{|c|c|c|c|c|c|}
\hline Вид & $\begin{array}{c}\text { Размер } \\
\text { кораллитов, } \\
\text { мм }\end{array}$ & $\begin{array}{l}\text { Размер ме- } \\
\text { зокоралли- } \\
\text { тов, } \boldsymbol{м м}\end{array}$ & $\begin{array}{l}\text { Толщина } \\
\text { стенок, } \\
\text { мм }\end{array}$ & $\begin{array}{c}\text { Интервал } \\
\text { днищ, } \\
\text { мм }\end{array}$ & $\begin{array}{l}\text { Септаль- } \\
\text { ные ши- } \\
\text { пики }\end{array}$ \\
\hline $\begin{array}{l}\text { H. catenularius } \\
\text { (Linnaeus) }\end{array}$ & $\begin{aligned} & 1,3-1,5 \times \\
\times & 1,6-1,9(2,1)\end{aligned}$ & $0,5 \times 0,75$ & $0,15-0,2$ & $0,4-1,7$ & $\begin{array}{l}12 \text { шт., } \\
\text { средней }\end{array}$ \\
\hline $\begin{array}{l}\text { H. cratus Etheri- } \\
\text { dge }\end{array}$ & $1,4 \times 1,6$ & $0,3 \times 0,8$ & 0,1 & $0,4-0,6$ & $\begin{array}{l}\text { величины } \\
\text { Не отме- } \\
\text { чены }\end{array}$ \\
\hline $\begin{array}{l}\text { H. pycnobiastoi- } \\
\text { des (sensu Ya- } \\
\text { be) }\end{array}$ & $1,5 \times 1,8$ & $0,3 \times 0,5$ & ? & $0,5-0,8$ & $\begin{array}{l}\text { Хорошо } \\
\text { развиты }\end{array}$ \\
\hline $\begin{array}{l}\text { H. catenularius } \\
\text { var. borealis } \\
\text { Tchern. }\end{array}$ & $\begin{array}{l}1,4-1,55 \times \\
\times 1,65-1,85\end{array}$ & $0,5 \times 0,5$ & $0,15-0,2$ & $0,25-0,7$ & $\begin{array}{l}\text { Многочис- } \\
\text { ленные, } \\
\text { короткие }\end{array}$ \\
\hline $\begin{array}{l}\text { H. priscus Klaa- } \\
\text { mann }\end{array}$ & $\begin{aligned} & 1,4-1,55 \times \\
& \times 1,6-1,8(2,0)\end{aligned}$ & $0,3 \times 0,5$ & $0,15-0,2$ & $0,4-0,7$ & $\begin{array}{l}\text { Редкие, } \\
\text { короткие }\end{array}$ \\
\hline
\end{tabular}

ЛИТЕРА Т У РА

Кл а а м ан н Э. Инкоммуникатные табуляты Эстонии. - Тр. Ин-та геол. АН ЭССР. Таллин, 1966.

Л елешус В. Л. Силурийские табуляты Памира. - Тр. Ин-та геол. АН Тадж. ССР, 1963 , т. 7 , c. $153-190$.

М и ронов а Н. В. Некоторые новые виды табулят и гелиолитид из верхнего силура Салаира и Горного Алтая. - В кн.: Табулятоморфные кораллы ордовика и силура СССР. М., 1965, с. $127-138$.

Ч ер ны ше в Б. Б. Верхнесилурийские и девонские Tabulata Новой Земли, Северной Земли и Таймыра. - Тр. Всес. Арк. ин-та, 1937, т. 91, с. 67-134.

B r o me 11, M. Lithographiae Svecanae. - Acta Liter. Svec., 1728, v. 2, p. 363-470.

Buehler, E. J. The morphology and taxonomy of the Halysitidae. - Bull. Peabody Mus. natur. hist., 1955 , v. 8 .

Etheridge, R. A monograph of the Silurian and Devonian corals of New South Wales. Part I. The Genus Halysites. - Mem. geol. Survey N.S.W. (Palaeont.), 1904 , v. 13. 
Grabau, A. W. Summary of the faunas from the Sintan Shale. - Bull. geol. Surv. China., 1925 , v. 7 , p. $77-85$.

$\mathrm{H}$ a mad a, T. On the classification of the Halysitidae. I, II. - J. Fac. Sci. Univ. Tokyo (2), 1957, v. 11, p. 393-430.

$\mathrm{H}$ a m a d a, T. Japanese Halysitidae. - J. Fac. Sci. Univ. Tokyo (2), 1958, v. 11, p. $91-114$.

Linnaeus, C. Systema naturae. (Editio Duodecima Reformata). Holmiae, 1767, p. 533-1327.

Oekentorp, K. Sekundärstrukturen bei paläozoischen Madreporaria. - Münster. Forsch. Geol. Paläont., 1972, Bd. 24, S. 35-108.

$\mathrm{T}$ hom a S, D., S m ith, S. The coral genus Halysites Fischer von Waldheim. - Ann. Mag. Natur. Hist., ser. 12,1954 , v. 7 , p. $765-774$.

$\mathrm{Y}$ a be, H. Einige Bemerkungen über die Halysites-Arten. - Sci. Rep. Tohoku Imp. Univ., 1915, Bd. 4, H. 1, S. 25-38.

$\mathrm{Y}$ abe, H., Hayas aka, I. Palaeozoic corals from Japan, Korea and China. - J. geol. Soc. Japan, 1915 , v. 22 , p. $55-142$.

$\mathrm{Yabe}$, H., H a y a s a ka, I. Palaeontology of Southern China. - Geogr. Res. China, 1911-1916. Rept. Tokyo Geogr. Soc., Tokyo, 1970.

\author{
Институт геологии \\ Академии наук Эстонской ССР
}

Поступила в редакцию $7 / \mathrm{V} 1979$

\title{
E. KLAAMANN
}

\section{HALYSITES CATENULARIUS'E (LINNAEUS) MORFOLOOGIA JA VANUS}

On esitatud neotüübi uurimisel ja Gotlandi siluri halüsitiidide revisjonil pōhinev perekonna Halysites tüüpliigi kirjeldus. Liigi stratigraafiline levik piirdub alamsiluri ländouveri ladejärguga, kust pärinevad nii Gotlandi saare leiud (alumine visby mergel) kui ka Halysites catenularius'ega sünonüümseks loetud liigid teistest piirkondadest.

\section{E. KLAAMANN}

\section{THE MORPHOLOGY AND GEOLOGICAL AGE OF HALYSITES CATENULARIUS (LINNAEUS)}

The author presents a description of the Halysites genotype, based on the research into the neotype and on the revision of halysitids of the Gotland Silurian. The stratigraphical distribution is limited to the Llandoverian stage of the Lower Silurian whence also the finds made in Gotland (Lower Visby marl) and those of species considered synonymous with Halysites catenularius (see the synonymics) in other regions. The diagnostical characters of the species are as follows: meshes outstretched, of varying shape; consist of corallites of $1.3-1.5 \mathrm{~mm}$ in width and $1.6-1.8$ in length. Mesocorallites mostly rectangular, $0.5-0.6 \times 0.75 \mathrm{~mm}$, the ioints of meshes irregularly triangular or polygonal (PI. II, Fig. 1). The corallite wall, $0.15-0.2 \mathrm{~mm}$ thick, consists of uniform, fine-grained calcium carbonate. Septa moderately developed, constantly 12 in number. Tabules horizontal, slightly concave or convex, placed at an interval of $0.4-0.7 \mathrm{~mm}$; mesocorallites are twice as densely diaphragmed.

A comparison of the quantitative characters of Halysites catenularius and synonymous species are presented in the Table. 